\title{
On Fragile Grounds: A replication of Are Muslim immigrants different in terms of cultural integration?
}

\author{
Mahmood Arai, ${ }^{*}$ Jonas Karlsson ${ }^{\dagger}$ and Michael Lundholm ${ }^{\ddagger}$
}

December 19, 2008

\begin{abstract}
This study is a replication of "Are Muslim Immigrants Different in terms of Cultural Integration?" by Alberto Bisin, Eleonora Patacchini, Thierry Verdier and Yves Zenou, published in Journal of European Economic Association, 6, 445-456, 2008.

Bisin et al. (2008) report that they have 5963 observations in their study. Using their empirical setup, we can only identify 1901 relevant observations in the original data. After removing missing values we are left with 818 observations. We cannot replicate any of their results and our estimations yield no support for their claims.
\end{abstract}

\section{Introduction}

This is a replication of the empirical results reported in Bisin et al. (2008). They use British data and analyse how Muslims and non-Muslims differ in cultural integration measured as (i) Importance of Religion, (ii) Attitude Towards Inter Marriage and (iii) Importance of Racial Composition in Schools. ${ }^{1}$

In the abstract of their paper they write:

"... Muslims integrate less and more slowly than non-Muslims.

... We also find no evidence that segregated neighbourhoods breed

* Corresponding author. Department of Economics and SULCIS, Stockholm University, SE 10691 Stockholm, Sweden, mahmood.arai@ne.su.se.

${ }^{\dagger}$ The Institute for Social Research and SULCIS, Stockholm University, jonas.karlsson@sofi.su.se.

${ }^{\ddagger}$ Department of Economics, Stockholm University, michael.lundholm@ne.su.se.

${ }^{1}$ To facilitate comparability we use the same labels on the variables as Bisin et al. (2008). 
intense religious and cultural identities for ethnic minorities, especially for Muslims." (Bisin et al., 2008, p. 245)

We wanted to check the robustness of their results when considering the ethnic and religious heterogeneity within both groups, Muslims and nonMuslims. Among other things, we were concerned about the measures of cultural values used in the paper. These measures capture ethnic and religious attributes in different degrees for different groups. For example the variable Attitudes towards Inter-Marriage with the majority UK population captures only inter-ethnic marriage for the Christian ethnic minorities but both inter-ethnic and inter-religious marriage for Muslims.

However, already an initial inspection of data disclosed that the number of observations in Bisin et al. (2008) exceeded the total number of observations in the ethnic minority sample. We communicated this to the authors and they answered that there were some coding errors. We have received revised codes and a revised version of their specifications and tables. Their revised codes yield fewer observations than the sample in the published version, but still more than we can identify in the relevant sample of the original data. As far as we can see, a source of the large number of observations in their revised codes is that dummy variable definitions include observations with missing values in the reference categories (defined as zeros). The underlying codes to the published paper were, however, not made available and the exact nature of the original errors are therefore unknown to us.

Bisin et al. (2008) report that they have 5963 observations in their study, whereas the ethnic minority sample in Berthoud et al. (1997) consists of 5226 observations. Implementing their empirical setup, we can only identify 1901 relevant observations in the original data. After removing missing values we are left with 818 observations. Using the remaining sample and running their specifications, we find no results that support their claims. Our replication therefore stopped here and we did not perform any sensitivity analysis. The great loss of observations implies that the remaining sample is most likely not representative. Therefore, we hesitate to draw inference from the regressions results.

In this paper we only document the replication and report and comment results using the variable definitions, the variable names and the specifications used in Bisin et al. (2008). We choose a procedure that makes it easy to reproduce our results. Influenced by Koenker and Zeileis (2007), we use an integrated approach where data management, estimations, and the text that rely on these computations are all integrated in one single file. This strategy has the advantage that it makes is easy to adjust the codes and automatically generate a revised version of the paper.

For details of our analysis of the data and implementation of the variable definitions, see Arai et al. (2008), which is a technical companion to this paper. All data analysis is made in $\mathrm{R}$ ( $\mathrm{R}$ Development Core Team, 2008) 
and all code files related to this project can be found on http://people. su.se/ ${ }^{\sim}$ lundh/fragile_grounds/.

The remainder of the paper is organised as follows. The data are described in Section 2. Regression results are presented in Section 3 and finally the paper is concluded in Section 4 .

\section{Data and variable description}

The data set is the Fourth National Survey of Ethnic Minorities 1993-1994 (FNSEM); see (Berthoud et al., 1997). ${ }^{2}$

In our definition of the relevant (ethnic minority) sample we have excluded (i) the UK majority population (defined as Whites in the data set), (ii) all who do not have a religion or do not belong to a church since they cannot be classified in a religious group, (iii) all singles since only people who are married or have been married answer the question about who made the final decision of their marriage and (iv) those who answered questionnaire "yellow" and "pink" since they do not answer relevant questions involved in the study. Table 1 compares the number of observations in this sample before and after non-availables are removed with the numbers of observations reported by the Bisin et al. (2008) study. The number of observations for various groups in the non-Muslim category are not reported in the Bisin et al. (2008) paper. These numbers are therefore missing in the table. The category definitions are from the original dataset and involves no recoding on our part.

After removing observations with missing values on all variables of interest ("After" in Table 1), we are left with 330 Muslims and 488 non-Muslims. The sample selections induced by the choice of variables and the missing values in these variables lead to a loss of 57 percent of the relevant sample of the original data. ${ }^{3}$

The sample means reported in Bisin et al. (2008) seem to be unweighted. Since data instructions says that the data should always be weighted, tables 2 and 3 report weighted and unweighted sample means before and after removal of non-availables and the Bisin et al. (2008) data. ${ }^{4}$ Comparing means, the Bisin et al. (2008) data seem to be different from the original sample. The variables Attitude Towards Inter Marriage and Importance of Racial Composition in Schools in Bisin et al. (2008) data deviate largely from corresponding averages in the original data. The deviation is extreme

\footnotetext{
${ }^{2}$ The data can be accessed from the UK Data Archive (UKDA) via Athens. UK Data Archive is found at http://www.data-archive.ac.uk/ and Athens at http://www . athens.ac.uk/.

${ }^{3}$ The variables written in capital letters are created to ensure well-defined reference categories. They are included in our regressions, but we cannot say whether they are included in the regressions of Bisin et al. (2008).

${ }^{4}$ See FNSEM (1993).
} 
in case of Importance of Racial Composition in Schools. The original sample has a mean for this variable that is 2 percent for non-Muslims (compare with 33 percent in Bisin et al. (2008)) and 6 percent for Muslims (compare with 65 percent in Bisin et al. (2008)). Due to this extremely skewed distribution. it is hardly meaningfull to run a regression on this variable,

Notice that also the distribution of the variable Importance of Religion would be extremely skewed using standard coding of this type of variables. Such a coding would imply that religion is important when the respondent answer "Very Important" and "Fairly Important", to the question "How important is religion to the way you live your life?".

The sample means in our data after removing accumulated missing values due to all variables in the estimations deviate marginally in general from the original data. The similarities here are partly due to the fact that the statistics are based exactly on the same variable definition in our implementation. In some respects, the deviations are larger. For further comparisons we refer to Tables 2 and 3 .

Due to the fact that the large majority of observations from the original data are lost, the remaining sample is likely to be contaminated with sample selection bias. To compare the characteristics of the remaining sample with the original sample says something about systematic attrition with respect to observables. The sample selection bias with respect to unobservables cannot, however, be resolved.

\section{$3 \quad$ Regression Results}

We use linear probability models (LPM). ${ }^{5}$ Our results are presented in Tables 4 and 5. Bisin et al. (2008) write that:

1. "Muslims integrate less and more slowly than non-Muslims." (abstract, p. 445) and

2. "... there is no evidence that segregated neighbourhoods breed intense religious and cultural identities. On the contrary, ... intense identities

\footnotetext{
${ }^{5}$ Bisin et al. (2008) use probit estimations. Our attempts to use probit run into convergence problems. The convergence problems are severe for the model using Importance of Racial Composition in Schools as dependent variable. Hence, our choice of LPM.

Another issue is that Bisin et al. (2008) should have included dummy variables indicating religious affiliation: Christians, Sikhs and others in the non-Muslim category to check similarities and differences among non-Muslims as well. In this respect we follow their model specification.

Moreover, Bisin et al. (2008) should have adjusted for within ward correlations. This might matter for their standard errors, which might be underestimated. In our case, with almost no significant results, this would not matter much. The variable is not available in the data set and we did not make much effort to obtain it.
} 
in our data are more prominent in relatively mixed neighbourhoods." (p. 446)

The first claim is based on their reported results concerning the variable Years Since Arrival. In this way Bisin et al. (2008) compare cohorts of Muslims and non Muslims and attempt to say something about the evolution of values over time. They do not follow individuals over time but nonetheless call these cohort differences "Integration over time". They report negative coefficients for Years Since Arrival, but the estimates are smaller in absolute value for Muslims than for non-Muslims. In our case, the coefficients for Years Since Arrival reported in Tables 4 and 5 are insignificant in all cases except in the regression for Importance of Religion for Muslims, where it is negative. This is opposite to what Bisin et al. (2008) claim.

The second claim is based on their reported results concerning the variable Ward Density Own Ethnicity. Bisin et al. (2008) report negative and significant estimates for Ward Density Own Ethnicity in all six specifications. Their negative coefficient for this variable would imply that ethnic minorities put more weight on religion, mind more about inter-ethnic marriage and have stronger taste for ethnically profiled schools, as we move from neighbourhoods (Wards) with high density of their own ethnicity to neighbourhoods where people from their own ethnicity are scarce. This is not at all what we find in our replication.

In our estimations, the estimated coefficients for this variable are all positive but far from significant. The $\mathrm{P}$-values are $0.69,0.97$ and 0.59 for Muslims and 0.15, 0.14 and 0.3 for non-Muslims contradicting the Bisin et al. (2008) results.

Inspecting the results presented in Tables 4 and 5, there are many similarities and few differences in the estimated coefficients for Muslims and non-Muslims. Our results are generally very different from results reported by Bisin et al. (2008). We are, however, doubtful whether it is possible to draw any reliable inference from these results due to great loss of observations and possible sample selection bias, together with the problem of endogeneity (also mentioned by Bisin et al. (2008)).

\section{Concluding remarks}

The Bisin et al. (2008) paper rests on fragile grounds. Our examination of the data using their variable definitions and the same set-up indicates that their claims about differences between Muslims and non-Muslims, and their conclusion that strong Religious/Ethnic identities are found in mixed neighbourhoods does not hold. There is no systematic relation between ethnic minorities' views on religion, inter-ethnic marriage or ethnic profile of schools and the density of their own ethnic minority in their neighbourhood. However, we hesitate to draw inference from these results since the great loss 
of observations (57 percent) implies that the remaining sample is most likely not representative.

\section{References}

Mahmood Arai, Jonas Karlsson, and Michael Lundholm. On fragile grounds: A replication of Are Muslim immigrants different in terms of cultural integration? Technical documentation. Unpublished manuscript, 2008.

R.G. Berthoud, T. Modood, P. Smith, and G. Prior. Fourth National Survey of Ethnic Minorities, 1993-1994 [computer file]. Colchester, Essex: UK, 1997. URL http://www.data-archive.ac.uk/doc/3685\%5Cmrdoc\% 5CUKDA\%5CUKDA_Study_3685_Information.htm. SN: 3685.

Alberto Bisin, Eleonora Patacchini, Thierry Verdier, and Yves Zenou. Are muslim immigrants different in terms of cultural integration? Journal of the European Economic Association, 6:445-456, 2008.

FNSEM. UK Data Archive Data Dictionary. Social andCommunity Planning Research, London, 1993. An RTF file called UKDA-3685-tab/mrdoc/ allissue/3685_UKDA_Data_Dictionary.rtf available when the FNSEM data set is downloaded from the UK Data Archive.

Roger Koenker and Achim Zeileis. Reproducible econometric research (a critical review of the state of the art). Report 60, Department of Statistics and Mathematics, Wirtschaftsuniversität Wien, Research Report Series, 2007. URL http:epub.wu-wien.ac.at/dyn/virlib/wp/eng/mediate/ epub-wu-01_c75.pdf?ID=epub-wu-01_c75.

R Development Core Team. R: A Language and Environment for Statistical Computing. R Foundation for Statistical Computing, Vienna, Austria, 2008. URL http://www.R-project.org. ISBN 3-900051-07-0. 


\section{Appendix: Tables}

Table 1: Religious affiliation (absolute (\#) and relative (\%) numbers), before (columns 1 and 2) and after (columns 3 and 4) removal of NA compared with Bisin et al. (2008) (columns 5 and 6).

\begin{tabular}{|c|c|c|c|c|c|c|}
\hline \multirow[t]{3}{*}{ Religious affiliation } & (1) & (2) & $(3)$ & (4) & (5) & $(6)$ \\
\hline & \multicolumn{2}{|c|}{$\begin{array}{c}\text { Before } \\
n=1901\end{array}$} & \multicolumn{2}{|c|}{$\begin{array}{c}\text { After } \\
n=818\end{array}$} & \multicolumn{2}{|c|}{$\begin{array}{c}\text { Bisin et al. } \\
n=5963\end{array}$} \\
\hline & $\#$ & $\%$ & $\#$ & $\%$ & $\#$ & $\%$ \\
\hline hindu & 359 & 18.88 & 149 & 18.22 & & \\
\hline sikh & 288 & 15.15 & 86 & 10.51 & & \\
\hline muslim & 852 & 44.82 & 330 & 40.34 & 2369 & 39.73 \\
\hline christian & 357 & 18.78 & 232 & 28.36 & & \\
\hline buddhist & 17 & 0.89 & 9 & 1.10 & & \\
\hline confucian & 1 & 0.05 & 1 & 0.12 & & \\
\hline jain & 7 & 0.37 & 3 & 0.37 & & \\
\hline parsi/zorastrian & 3 & 0.16 & 2 & 0.24 & & \\
\hline rastafarian & 2 & 0.11 & 1 & 0.12 & & \\
\hline jewish & 1 & 0.05 & 0 & 0.00 & & \\
\hline other & 10 & 0.53 & 5 & 0.61 & & \\
\hline na & 0 & 0.00 & 0 & 0.00 & & \\
\hline NA's & 4 & 0.21 & 0 & 0.00 & & \\
\hline All non-Muslims & 1045 & 55.09 & 488 & 59.66 & 3594 & 60.27 \\
\hline
\end{tabular}




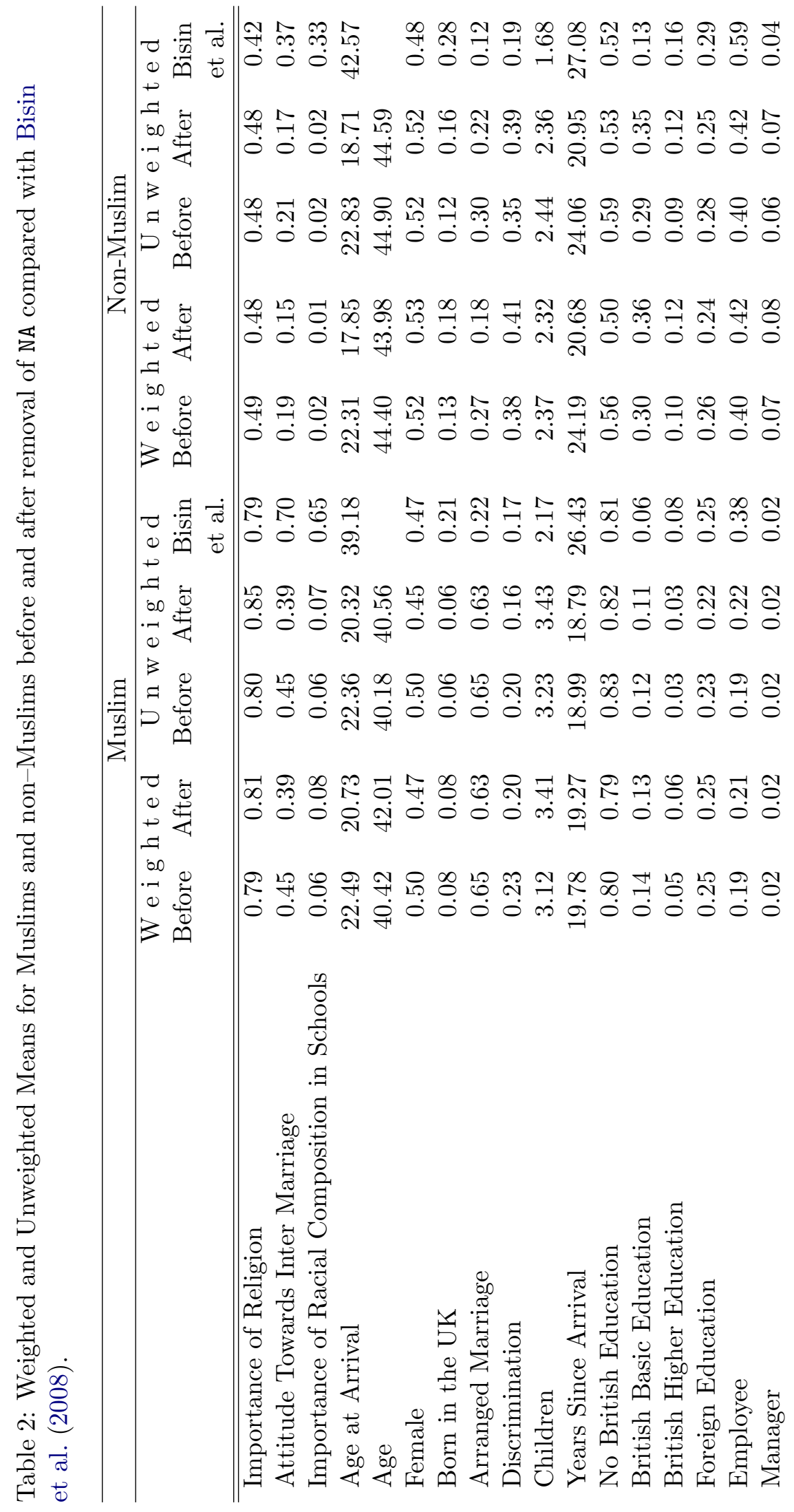




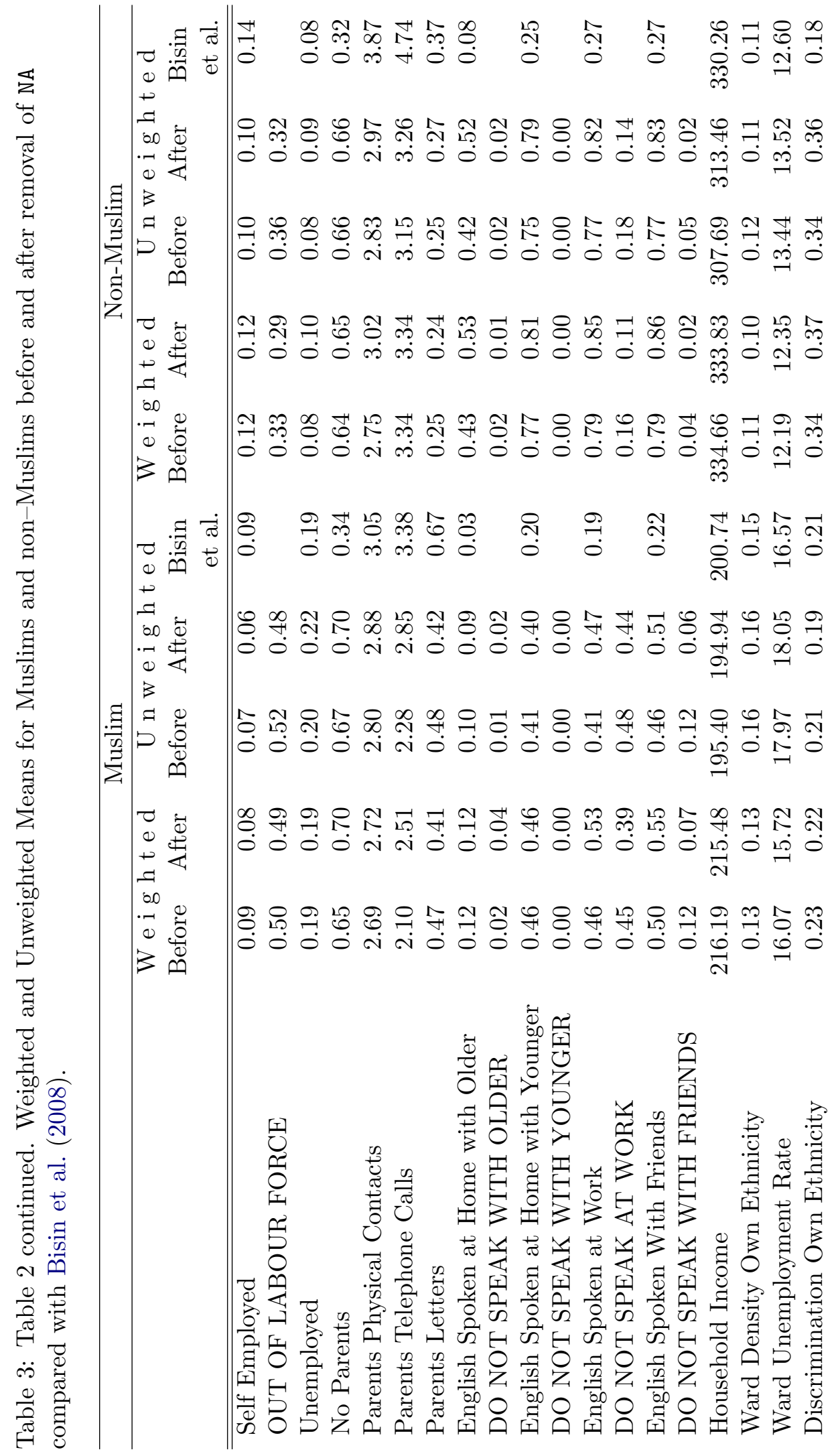




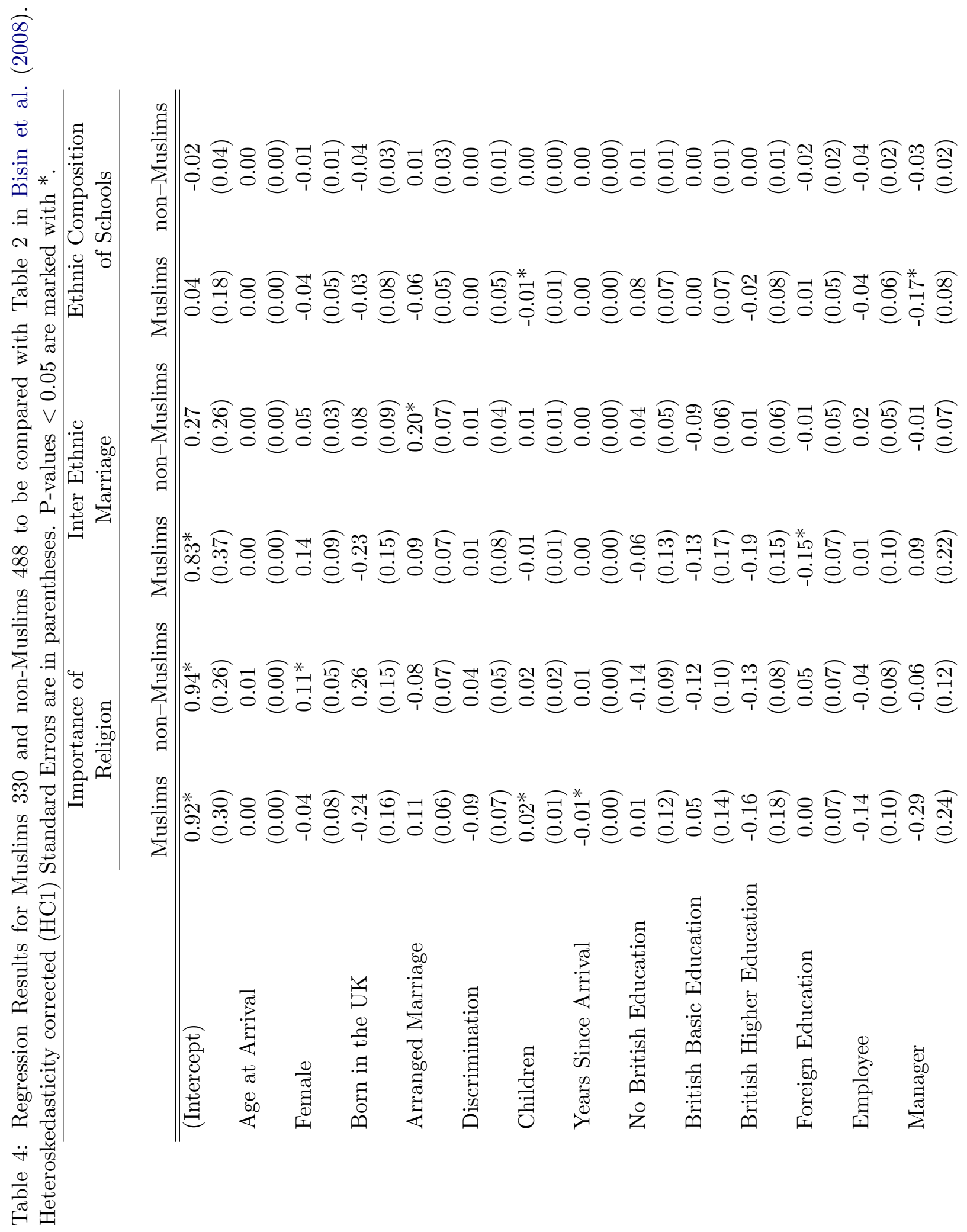




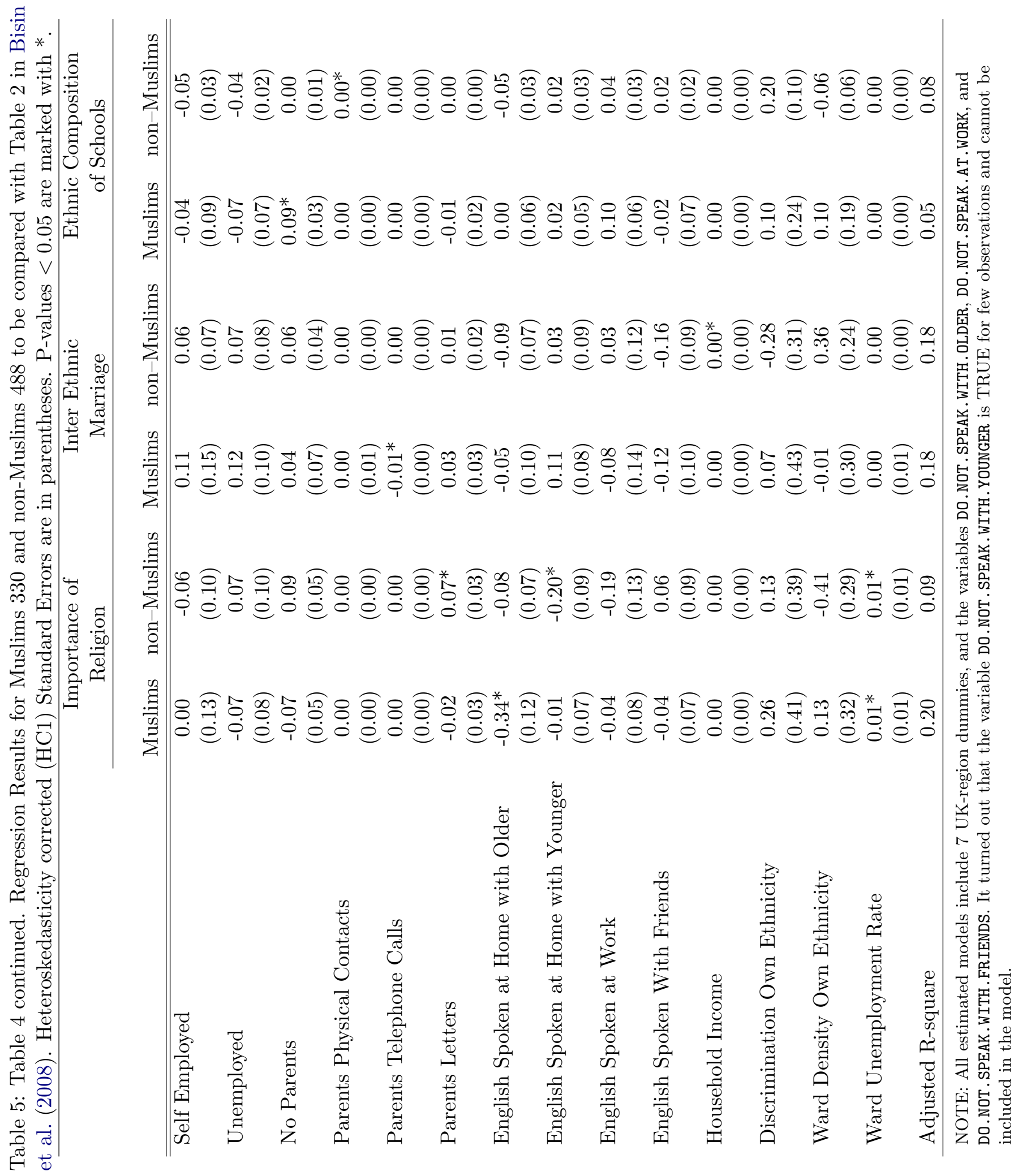

